This item was submitted to Loughborough's Research Repository by the author.

Items in Figshare are protected by copyright, with all rights reserved, unless otherwise indicated.

\title{
Changes in perceptions of mental fatigue during a season in professional under-23 English Premier League soccer players
}

\section{PLEASE CITE THE PUBLISHED VERSION}

https://doi.org/10.1080/15438627.2020.1784176

\section{PUBLISHER}

Informa UK Limited, trading as Taylor \& Francis Group

VERSION

AM (Accepted Manuscript)

\section{PUBLISHER STATEMENT}

This is an Accepted Manuscript of an article published by Taylor \& Francis in Research in Sports Medicine on 30 June 2020, available online: http://www.tandfonline.com/10.1080/15438627.2020.1784176.

\section{LICENCE}

CC BY-NC-ND 4.0

\section{REPOSITORY RECORD}

Abbott, William, Thomas E Brownlee, Robert J Naughton, Tom Clifford, Richard Page, and Liam D Harper. 2020. "Changes in Perceptions of Mental Fatigue During a Season in Professional Under-23 English Premier League Soccer Players”. Loughborough University. https://hdl.handle.net/2134/12593312.v1. 
1 Title: Changes in perceptions of mental fatigue during a season in professional under-23 English

2

Premier League soccer players

3

4

5

6

7

8

9

10

11

12

13

14

15

16

17

18 


\section{Abstract}

The present study assessed changes in academy soccer players' perception of mental fatigue (MF) across a competitive season, investigating the relationship between MF and other subjective measures of wellness. Ten players completed a modified Brief Assessment of Mood (BAM+) questionnaire that included the question: 'How mentally fatigued do you feel'? on match-day (MD) and one (MD+1), two $(M D+2)$ and three $(M D+3)$ days post-match (35 matches). Players reported their MF, along with other subjective measures (sleep, muscle soreness, fatigue and motivation). Results found MF was elevated on $\mathrm{MD}+1(43 \pm 1 \mathrm{~mm})$ compared to all other days (all $\mathrm{P} \leq 0.001)$. Players reported lower MF on $\mathrm{MD}+1$ in the late-season phase $(34 \pm 2 \mathrm{~mm})$ compared to both early- $(50 \pm 2 \mathrm{~mm}, \mathrm{P} \leq 0.001)$ and midseason $(46 \pm 2 \mathrm{~mm}, \mathrm{P} \leq 0.001)$. This coincided with an $80 \%$-win rate in the late-season phase versus the early- (33\%) and mid-season (50\%). There were very strong repeated-measures correlations between changes in MF and sleep $(r=-0.77)$, muscle soreness $(r=0.94)$, fatigue $(r=0.92)$ and motivation $(r=-$ 0.89; all $\mathrm{P} \leq 0.0005)$. In conclusion, MF was closely aligned to match success and other wellness variables. This data suggests a potential lack of sensitivity for identifying MF using a subjective questionnaire. Therefore, researchers and practitioners could work together to identify other ways of practically assessing MF.

Keywords: football, monitoring, recovery, cognition, affect, visual analogue scale 
41 Soccer match-play is a physically and cognitively demanding activity, requiring players to process

42 information such as the location of the ball, their teammates and opponents, and thus perform appropriate physical movements and skill actions (within the tactical constraints imposed by the coaching staff, field space and opposition; Coutts, 2016; Smith et al., 2018) This may not only lead to physical fatigue, but also mental fatigue. Mental (or cognitive) fatigue is considered a psychobiological state, resulting in a reduced ability to perform cognitive and behavioural tasks, with associated feelings of lethargy and demotivation (Boksem \& Tops, 2008; Marcora, Staiano, \& Manning, 2009; McMorris, Barwood, Hale, Dicks, \& Corbett, 2018). Physical performance in laboratory-controlled conditions may be reduced when mentally fatigued (Marcora et al., 2009; Smith, Coutts, et al., 2016; Smith, Marcora, \& Coutts, 2015) (although it may depend on the type and duration of exercise; Duncan, Fowler, George, Joyce, \& Hankey, 2015; Martin, Thompson, Keegan, Ball, \& Rattray, 2015). Similarly equivocal findings have been reported during soccer small-sided games, with one study observing reduced physical activity profiles (Coutinho et al., 2018), whilst others have observed no differences in running performance despite increased ratings of perceived exertion (Badin, Smith, Conte, \& Coutts, 2016; Coutinho et al., 2017). Some aspects of technical (Badin et al., 2016; Smith, Coutts, et al., 2016; Smith, Fransen, Deprez, Lenior, \& Coutts, 2017), tactical (Coutinho et al., 2017; Coutinho et al., 2018), and perceptualcognitive performance (Smith, Zeuwts, et al., 2016) are negatively affected by mental fatigue. However, researchers have experimentally induced mental fatigue through the use of cognitively demanding tasks, such as the Stroop Test, with one previous study utilising an agility-focused motor task (Coutinho et al., 2018). The ecological validity of these types of tasks in an applied soccer setting 
is questionable, though the neurobiological and physiological response to mental fatigue has been shown not to differ dependent on the source of inducement (i.e. traditional mental fatigue task vs. applied environment). However, there is scope to investigate the impact of normal day-to-day practices of soccer players on mental fatigue. periods of fixture congestion where they may be required to play three matches in seven days (Carling et al., 2015). Changes in performance, injury risk and objective and subjective wellness/recovery have been assessed during a competitive season (Abbott, Brownlee, Harper, Naughton, \& Clifford, 2018; Abbott et al., 2019; Slater et al., 2018). However, changes in perceptions of mental fatigue across a season have not been previously investigated, despite anecdotal evidence of players and coaches previously citing the mentally fatiguing nature of professional soccer, particularly towards the end of the season. Furthermore, contextual variables such as match location, strength of opposition and match outcome have been shown to differentially affect subjective measures of wellness and fatigue post-match (Abbott et al., 2018). However, the influence of these factors on mental fatigue has not been investigated. Therefore, the aim of this study was to assess changes in perception of mental fatigue across a competitive season in under- 23 professional soccer players. Furthermore, the influence of soccer-specific contextual variables was investigated, as well as the relationship between mental fatigue and other subjective measures of wellness. 
The study conformed with The Code of Ethics of the World Medical Association and received ethical approval from the University of Huddersfield School of Human and Health Sciences ethics committee. All players provided written informed consent prior to data collection.

Ten under-23 male soccer players $(20 \pm 1$ years, $180 \pm 7 \mathrm{~cm}, 78.5 \pm 8.7 \mathrm{~kg}, \mathrm{n}=4$ international level [U19 or above]) participated in this study during the 2017-2018 English Premier League 2 Division 2 season. Data was collected from a total of 24 players; however, 14 players' data was not analysed due to playing $<50 \%$ of matches. This was due to injury, international duty, or loans to other clubs. The players completed a Brief Assessment of Mood (BAM+; Shearer et al., 2017)) questionnaire in the morning ( 9.30am) on match-day (MD), the day after a match (MD+1), as well two and three days after $(\mathrm{MD}+2$ and $\mathrm{MD}+3)$. The $\mathrm{BAM}+$ was adapted to include an eleventh question: 'How mentally fatigued do you feel?' with a $100 \mathrm{~mm}$ visual analogue scale anchored with 'not at all' and 'extremely'. Players were instructed to draw a line on the scale at the point that best represented how they felt at that time. In order to overcome self-assessment bias and the players' potential lack of metacognition (Thompson et al., 2019), a clear and uniform definition of mental fatigue was provided based on Marcora et al., (2009): 'a reduced ability to perform cognitive and behavioural tasks with feelings of lethargy'. The following variables from the BAM+ were also analysed: sleep (how well do you feel you have slept?), muscle soreness (how sore do your muscles feel?), fatigue (how fatigued do you feel?), and motivation (how motivated to train do you feel?). Players only completed the modified BAM + if they played $>45$ minutes in a match. A total of 35 matches were included (two matches that required extra-time were excluded from analyses due to the 
potential influence on recovery (Winder, Russell, Naughton, \& Harper, 2018)), resulting in 201 player observations.

The following contextual variables were considered in analyses: season-phase (early [first 12 matches, August-October], mid [12 matches, November-January] and late [last 11 matches, FebruaryApril]), match outcome (win, draw or loss), days off training post-match (one or two), quality of opposition (top- $\left[1^{\text {st }}-4^{\text {th }}\right.$ or division above $]$, mid- $\left[5^{\text {th }}-8^{\text {th }}\right]$ and bottom- $\left[9^{\text {th }}-12^{\text {th }}\right.$ or division(s) below $]$ table), match location (home or away) and fixture congestion ( $\leq 3$ days or $>3$ days between matches). Linear mixed models (LMM) were used to examine the influence of different contextual factors (location, result, level of opposition, phase of the season, fixture congestion, and the number of days off during the weekly microcycle) on the dependent variables (mental fatigue, motivation, sleep, fatigue and muscle soreness) recorded across the different match day codes (MD, MD+1, MD+2, and MD+3). An LMM was utilised to overcome the assumption of independence, and also because of the flexibility that this method has in accounting for the altering sample sizes between groups with repeated measures. Before running the LMM, basic variance components analysis was performed on each dependent variable assess if the random factors of player and match contributed significant variance. Given the large number of individual match observations, Wald Z statistics were utilised to test the null hypothesis that the population variance is zero, if rejected the proposed random factors were included in subsequent larger models. The covariance structure of the random factors was set to variance components in all models. Model fit was assessed using Akaike's information criterion (AIC). For the dependent variable of mental fatigue, the AIC revealed the model that best fit the data utilising the first order autoregressive (AR-1) repeated covariance structure for the repeated measures. The fixed effects and their interactions in each model included the contextual factor and match day code. All models estimated 
parameters using the maximum likelihood method. Where appropriate, LSD adjusted post hoc analyses

127 and the respective $95 \%$ confidence intervals $(95 \% \mathrm{CI})$ of the differences were reported. Unless

128 otherwise stated, data is presented as means and standard error (SE), with mean differences (Mdiff)

129 presented as a measure of effect size where appropriate. All statistical procedures were carried out using

130 IBM SPSS Statistics (Version 25, Chicago, IL, USA), with two-tailed significance being accepted at

$131 \mathrm{P}<0.05$. Repeated measures correlations were conducted using rmcorr (Bakdash \& Marusich, 2017) in

132 R Studio (Version 1.1.463, RStudio Inc., Boston, MA) to investigate relationships between ratings of mental fatigue and other BAM+ variables over time.

134

135

136

137

138

139

140

141

142

143

144 


\section{Variance Calculations}

The basic variance components analysis for the random factors of player and match and was used to determine if any contributed significant variance. For the current study, only match was included as a random factor for the mental fatigue data. For measures of sleep, motivation, fatigue, and muscle soreness, neither player or match were included as random factors.

$\mathrm{CI}_{\text {diff }}=14$ to 19$), \mathrm{MD}+2\left(\mathrm{P} \leq 0.001 ; 32 \pm 1 \mathrm{~mm} ;\right.$ Mdiff $=11 ; 95 \% \mathrm{CI}_{\text {diff }}=9$ to 14$)$ and $\mathrm{MD}+3(\mathrm{P} \leq 0.001$;

$29 \pm 1 \mathrm{~mm} ;$ Mdiff $=14 ; 95 \% \mathrm{CI}_{\text {diff }}=12$ to 16$)$. Mental fatigue was also higher on $\mathrm{MD}+2$ compared to

$\mathrm{MD}\left(\mathrm{P} \leq 0.001 ;\right.$ Mdiff $=5 ; 95 \% \mathrm{CI}_{\mathrm{diff}}=3$ to 7$)$ and $\mathrm{MD}+3\left(\mathrm{P}=0.025 ;\right.$ Mdiff $=3 ; 95 \% \mathrm{CI}_{\mathrm{diff}}=0$ to 5$)$.

Furthermore, mental fatigue was higher on $\mathrm{MD}+3$ than $\mathrm{MD}\left(\mathrm{P}=0.045 ;\right.$ Mdiff= $3 ; 95 \% \mathrm{CI}_{\text {diff }}=3$ to 5$)$.

\section{Influence of Contextual factors}

There was a significant phase of the season by MD code interaction $(\mathrm{P} \leq 0.001)$, with significantly higher mid-season phase ( $\mathrm{P} \leq 0.001 ; 46 \pm 2 \mathrm{~mm} ;$ Mdiff $=12 ; 95 \% \mathrm{CI}_{\text {diff }}=6$ to 19$)$ compared to the late-season phase (34 $\pm 2 \mathrm{~mm}$; Table 1). Significantly higher values were also recorded on MD+2 during the earlyseason phase $\left(\mathrm{P}=0.023 ; 36 \pm 2 \mathrm{~mm}\right.$; Mdiff $=8 ; 95 \% \mathrm{CI}_{\text {diff }}=1$ to 15$)$ when compared to the late-season phase $(28 \pm 2 \mathrm{~mm}$; Table 1$)$. 
There was a significant match outcome by MD code interaction $(\mathrm{P} \leq 0.001)$, with significantly higher values recorded on $\mathrm{MD}+1$ following a loss $\left(\mathrm{P} \leq 0.001 ; 54 \pm 3 \mathrm{~mm} ;\right.$ Mdiff $=17 ; 95 \% \mathrm{CI}_{\text {diff }}=10$ to 24$)$ or a draw $\left(\mathrm{P} \leq 0.001 ; 48 \pm 2 \mathrm{~mm} ;\right.$ Mdiff $=11 ; 95 \% \mathrm{CI}_{\text {diff }}=6$ to 17$)$ when compared to a win $(37 \pm 2 \mathrm{~mm}$; Table a win $\left(\mathrm{P} \leq 0.001 ; 29 \pm 2 \mathrm{~mm} ;\right.$ Mdiff $=13 ; 95 \% \mathrm{CI}_{\text {diff }}=7$ to 20$)$ or a draw $(\mathrm{P} \leq 0.001 ; 30 \pm 2 \mathrm{~mm}$; Mdiff $=$ $12 ; 95 \% \mathrm{CI}_{\text {diff }}=5$ to 20 ; Table 1$)$.

There was a significant opposition level by MD code interaction $(\mathrm{P} \leq 0.001)$, with significantly higher values recorded on $\mathrm{MD}+1\left(\mathrm{P} \leq 0.001 ;\right.$ Mdiff $=10 ; 95 \% \mathrm{CI}_{\text {diff }}=4$ to 16$)$ when playing against middle-table opposition ( $49 \pm 3 \mathrm{~mm}$ ) compared to top-table opposition (39 $\pm 2 \mathrm{~mm}$; Table 1). The opposite response was observed on $\mathrm{MD}+3\left(\mathrm{P}=0.003 ;\right.$ Mdiff $=9 ; 95 \% \mathrm{CI}_{\mathrm{diff}}=3$ to 15$)$, with higher values observed when playing top-table opposition ( $33 \pm 2 \mathrm{~mm})$ when compared to mid-table opposition ( $23 \pm 3 \mathrm{~mm}$; Table $1)$.

There was a significant days off by MD code interaction ( $\mathrm{P}=0.004)$, with significantly $(\mathrm{P}=0.027$; Mdiff $=$ 6; $95 \% \mathrm{CI}_{\text {diff }}=1$ to 10$)$ higher values recorded on $\mathrm{MD}+1$ with two days off ( $46 \pm 2 \mathrm{~mm}$ ) compared to one day off ( $40 \pm 2 \mathrm{~mm}$; Table 1). Furthermore, there was a significant fixture congestion by MD code interaction ( $\mathrm{P} \leq 0.001)$, with significantly $\left(\mathrm{P}=0.003 ;\right.$ Mdiff $=8 ; 95 \% \mathrm{CI}_{\text {diff }}=3$ to 13$)$ higher values recorded on $\mathrm{MD}+1$ following a match preceded by more than three days' rest $(46 \pm 2 \mathrm{~mm})$ when compared to a match preceded by three or less days rest $(38 \pm 2 \mathrm{~mm}$; Table 1$)$. There was also a significant match 
location by MD code interaction ( $\mathrm{P} \leq 0.001)$, with significantly $\left(\mathrm{P}=0.008 ;\right.$ Mdiff $=8 ; 95 \% \mathrm{CI}_{\text {diff }}=2$ to 14$)$ higher values recorded on $\mathrm{MD}+1$ following a home match $(47 \pm 2 \mathrm{~mm})$ when compared to an away match $(39 \pm 2 \mathrm{~mm}$; Table 1).

When analysing all matches, there was a significant time effect for sleep, muscle soreness, fatigue and motivation (all $\mathrm{P} \leq 0.001$; see Table 2 for interaction effects). Subjective ratings of muscle soreness were elevated on $\mathrm{MD}+1(58 \pm 1 \mathrm{~mm})$ compared to $\mathrm{MD}(\mathrm{P} \leq 0.001 ; 29 \pm 1 \mathrm{~mm} ; \mathrm{M}$ diff $=28$, $95 \% \mathrm{CI}_{\text {diff }}=23$ to 33$), \mathrm{MD}+2\left(\mathrm{P} \leq 0.001 ; 40 \pm 1 \mathrm{~mm} ; \mathrm{M}\right.$ diff $=17,95 \% \mathrm{CI}_{\text {diff }}=12$ to 21$)$ and $\mathrm{MD}+3$ $\left(\mathrm{P}=0.014 ; 32 \pm 1 \mathrm{~mm} ; \mathrm{M} d i f f=26,95 \% \mathrm{CI}_{\text {diff }}=20\right.$ to 31$)$. Subjective ratings of fatigue were elevated on $\mathrm{MD}+1(58 \pm 2 \mathrm{~mm})$ compared to $\mathrm{MD}\left(\mathrm{P} \leq 0.001 ; 27 \pm 1 \mathrm{~mm} ; \mathrm{M} d i f f=31,95 \% \mathrm{CI}_{\text {diff }}=26\right.$ to 36$)$ and $\mathrm{MD}+2\left(\mathrm{P} \leq 0.001 ; 41 \pm 2 \mathrm{~mm} ; \mathrm{M} d i f f=18,95 \% \mathrm{CI}_{\text {diff }}=14\right.$ to 21$)$, with no differences at $\mathrm{MD}+3(30 \pm 1$ $\mathrm{mm}, \mathrm{P}=0.434)$.

Subjective ratings of sleep were lower on $\mathrm{MD}+1(46 \pm 1 \mathrm{~mm})$ compared to $\mathrm{MD}(\mathrm{P} \leq 0.001 ; 59$ $\pm 2 \mathrm{~mm} ; 95 \% \mathrm{M} d i f f=13,95 \% \mathrm{CI}_{\text {diff }}=8$ to 18$)$ and compared to $\mathrm{MD}+3(\mathrm{P} \leq 0.001 ; 55 \pm 1 \mathrm{~mm} ; \mathrm{M}$ diff $=$ $9,95 \% \mathrm{CI}_{\text {diff }}=2$ to 15$)$, with no difference on $\mathrm{MD}+2(59 \pm 1 \mathrm{~mm}, \mathrm{P}=1.000)$. Motivation to train was lower on $\mathrm{MD}+1(36 \pm 2 \mathrm{~mm})$ compared to $\mathrm{MD}\left(\mathrm{P} \leq 0.001 ; 53 \pm 1 \mathrm{~mm} ; \mathrm{M}\right.$ diff $=16,95 \% \mathrm{CI}_{\text {diff }}=9$ to 23), but no differences were observed on $\mathrm{MD}+2(48 \pm 1 \mathrm{~mm}, \mathrm{P}=0.060)$ or $\mathrm{MD}+3(51 \pm 2 \mathrm{~mm}$, $\mathrm{P}=1.000$ ). Irrespective of the contextual variables, there was a significant repeated-measures correlation between mental fatigue and: sleep $(r=-0.77 ; \mathrm{P} \leq 0.001)$, muscle soreness $(r=0.94$; $\mathrm{P} \leq 0.001)$, fatigue $(r=0.92 ; \mathrm{P} \leq 0.001)$, and motivation $(r=-0.89 ; \mathrm{P} \leq 0.001)$. 
This is the first study to measure perceptions of mental fatigue across a competitive season in professional soccer academy players. The main findings are: 1) mental fatigue is elevated for two days following a match, 2) a number of contextual variables influence this response, in particular, match outcome, 3) subjective ratings of mental fatigue are closely related to other subjective measures of wellness. phase compared to both the early- and mid-season phase. Whilst this is the first study to track changes in mental fatigue during a season and so comparisons to other published research is not possible, players and coaches have been cited in the media highlighting increased mental fatigue towards the end of the season (albeit anecdotal evidence). Moreover, elite Australian athletes have cited a cumulative effect of mental fatigue across the course of a season. However, the club involved in this present study won $80 \%$ (9 out of 11) of matches in the final third of the season, putting themselves in the playoff stage and winning promotion from the league. In comparison, in the early- and mid-season phases, the club won $33 \%$ and $50 \%$ of matches, respectively. More acutely, players reported higher mental fatigue on $\mathrm{MD}+1$ following a loss or draw versus a win (Table 1), which persisted at MD +2 players' perception of mental fatigue, regardless of season phase.

Although there were very strong correlations between mental fatigue and the other subjective measures irrespective of contextual variables, some did not follow a similar pattern based on match outcome. Both sleep and motivation to train were not acutely affected by losing and were actually 
higher in the early-season phase compared to the mid- and late-season phases (Table 2). Nevertheless, muscle soreness was higher on $\mathrm{MD}+2$ following a loss, and fatigue was higher on both $\mathrm{MD}+1$ and $\mathrm{MD}+2$ after losing. Interestingly, players reported lower fatigue and muscle soreness in the lateseason phase on $\mathrm{MD}+1$ and $\mathrm{MD}+2$ compared to the early-season phase (and on MD+1 vs. mid-season phase) which is contrary to previous investigations, who, similar to the present study, identified impaired subjective wellness following a loss compared to a win, but no differences in muscle soreness or fatigue (Abbott et al., 2018). One explanation may be the players completing the BAM+ in a 'socially desirable' manner during the late-season phase, when the club was winning matches and in a position to try and gain promotion. The players may have potentially rated themselves less fatigued and sore to demonstrate they were coping well and would not reduce their chances of being selected in the starting eleven . Perhaps, the most simple explanation is that a winning environment creates a positive environment for players, which may 'override' any feeling of mental fatigue.

241 Players reported higher perceptions of mental fatigue, muscle soreness and fatigue on $\mathrm{MD}+1$

242 following matches against mid-table opposition compared to top-table opposition, as well as greater feelings of mental fatigue on MD+1 following home matches compared to away matches (Table 1).

244 These findings are contradictory to previous research that has shown that playing against stronger or equal opponents is both more physically and technically difficult than playing against lower-level opposition, and leads to impaired subjective wellness (Abbott et al., 2018). Again, match outcome may go some way in explaining these results, with the club winning $67 \%$ of matches versus top-table opposition compared to $38 \%$ when playing mid-table opposition. Furthermore, the club had a higher 
susceptibility to mental fatigue. This may be due to differences in intellect, with athletes who have a

higher intellect more likely to suffer from greater mental fatigue (through overthinking). Furthermore, present study had participants with an average age of $20 \pm 1$ years, mental fatigue may have been more apparent due to their relative lack of experience playing at a professional level. Practitioners and coaches should be cognisant of which athletes may be most vulnerable to the effects of mental cognitive demand, such as reviewing of video footage and tactical drills. such, coaches and practitioners should be conscious of the stimuli that players/athletes are exposed to, ensuring training tasks are sufficiently varied and stimulating, whilst avoiding cognitive overload. mental fatigue, including enthusiasm, (dis)engagement, and concentration . available and whilst we did provide a definition to the players, it is difficult to completely distinguish mental fatigue from other BAM + variables (lethargy is also related to fatigue and motivation). 
players' perception of mental fatigue has been used in previous research (Smith, Coutts et al., 2016;

273 Smith, Zeuwts et al., 2016) it has not been fully validated and as such there is scope for a validation

274 study of this measure. The English Premier League 2 Division 2 club that participated in this study

275 competed in 37 matches over the course of the season. This is considerably lower than what some

276 other clubs, particularly at the adult professional level, would compete in during a season (potentially

277 up to 60 matches; Carling et al., 2015). This is not including matches that players may participate in

278 for their national team. Therefore, assessing whether a greater number of matches across a season

279 contributes to increased sensations of mental fatigue remains to be investigated. effect between mental fatigue and sleepiness (Smith et al., 2018). Finally, the findings may only be representative of this particular group of players, the practices of the club and the way the season 
- Changes in perceptions of mental fatigue seem to be closely associated with match success (i.e., lower ratings of mental fatigue following a win compared to a loss or draw), so practitioners and coaches should be cognisant of this when prescribing training with complex information in the days following a draw or a loss.

- A subjective measure of mental fatigue is closely correlated with other subjective measures including sleep, muscle soreness, fatigue and motivation to train, as such, more sensitive measures of measuring mental fatigue may be required.

- If deemed necessary, practitioners and researchers should work together to identify a sensitive and ecologically valid tool to measure mental fatigue, as well as potential interventions that improve perceptions of fatigue.

- Subjective measures of wellness can be used in decision-making regarding training prescription.

- The findings may only be representative of this group of players and the methods employed at the club; therefore, future research may benefit from a multi-club approach and as such, we encourage practitioners to engage with researchers and colleagues to facilitate this. 
Whilst acknowledging that the findings may only be representative of this group of players in this

317 particular season, perception of mental fatigue acutely increases following matches, and is linked to match outcome. Subjective measures of wellness can be used effectively to identify when players may need an extra day off training. If deemed necessary, researchers should work with practitioners to identify sensitive measures of mental fatigue that can be used effectively in the field. Occam's Razor may not exist in relation to mental fatigue, and more sophisticated objective measures with high sensitivity may be required. However, a cost-benefit analysis and an assessment of the practical application of such measures is required. 
Abbott, W., Brownlee, T. E., Harper, L. D., Naughton, R. J., \& Clifford, T. (2018). The independent effects of match location, match result and the quality of opposition on subjective wellbeing in under 23 soccer players: a case study. Res Sports Med, 26(3), 262-275. doi:10.1080/15438627.2018.1447476

Abbott, W., Brownlee, T. E., Harper, L. D., Naughton, R. J., Richardson, A., \& Clifford, T. (2019). A season long investigation into the effects of injury, match selection and training load on mental wellbeing in professional under 23 soccer players: A team case study. Eur J Sport Sci, 1-7. doi:10.1080/17461391.2019.1600586

Badin, O. O., Smith, M. R., Conte, D., \& Coutts, A. J. (2016). Mental Fatigue: Impairment of Technical Performance in Small-Sided Soccer Games. Int J Sports Physiol Perform, 11(8), 1100-1105. doi:10.1123/ijspp.2015-0710

Bakdash, J. Z., \& Marusich, L. R. (2017). Repeated Measures Correlation. Front Psychol, 8, 456. doi:10.3389/fpsyg.2017.00456

Boksem, M. A., Meijman, T. F., \& Lorist, M. M. (2006). Mental fatigue, motivation and action monitoring. Biol Psychol, 72(2), 123-132. doi:10.1016/j.biopsycho.2005.08.007

Boksem, M. A., \& Tops, M. (2008). Mental fatigue: costs and benefits. Brain Res Rev, 59(1), 125139. doi:10.1016/j.brainresrev.2008.07.001

Carling, C., Gregson, W., McCall, A., Moreira, A., Wong del, P., \& Bradley, P. S. (2015). Match running performance during fixture congestion in elite soccer: research issues and future directions. Sports Med, 45(5), 605-613. doi:10.1007/s40279-015-0313-z

Coutinho, D., Goncalves, B., Travassos, B., Wong, D. P., Coutts, A. J., \& Sampaio, J. E. (2017). Mental Fatigue and Spatial References Impair Soccer Players' Physical and Tactical Performances. Front Psychol, 8, 1645. doi:10.3389/fpsyg.2017.01645

Coutinho, D., Goncalves, B., Wong, D. P., Travassos, B., Coutts, A. J., \& Sampaio, J. (2018). Exploring the effects of mental and muscular fatigue in soccer players' performance. Hum Mov Sci, 58, 287-296. doi:10.1016/j.humov.2018.03.004

Coutts, A. J. (2016). Fatigue in football: it's not a brainless task! J Sports Sci, 34(14), 1296. doi:10.1080/02640414.2016.1170475

Duncan, M. J., Fowler, N., George, O., Joyce, S., \& Hankey, J. (2015). Mental fatigue negatively influences manual dexterity and anticipation timing but not repeated high-intensity exercise performance in trained adults. Res Sports Med, 23(1), 1-13. doi:10.1080/15438627.2014.975811

Fessi, M. S., \& Moalla, W. (2018). Postmatch Perceived Exertion, Feeling, and Wellness in Professional Soccer Players. Int J Sports Physiol Perform, 13(5), 631-637. doi:10.1123/ijspp.2017-0725

Lago, C., Casais, L., E., D., \& Sampaio, J. (2010). The effects of situational variables on distance covered at various speeds in elite soccer. Eur J Sport Sci, 10(2), 103-109.

Marcora, S. M., Staiano, W., \& Manning, V. (2009). Mental fatigue impairs physical performance in humans. J Appl Physiol (1985), 106(3), 857-864. doi:10.1152/japplphysiol.91324.2008

Martin, K., Thompson, K. G., Keegan, R., Ball, N., \& Rattray, B. (2015). Mental fatigue does not affect maximal anaerobic exercise performance. Eur J Appl Physiol, 115(4), 715-725. doi:10.1007/s00421-014-3052-1

McMorris, T., Barwood, M., Hale, B. J., Dicks, M., \& Corbett, J. (2018). Cognitive fatigue effects on physical performance: A systematic review and meta-analysis. Physiol Behav, 188, 103-107. doi:10.1016/j.physbeh.2018.01.029

Rago, V., Silva, J., Mohr, M., Randers, M., Barreira, D., Krustrup, P., Rebelo, A. (2018). Influence of oppoment standard on activity profile and fatigue development during preseasonal friendly soccer matches: a team study. Res Sports Med, 26, 413-424.

Russell, S., Jenkins, D., Rynne, S., Halson, S. L., \& Kelly, V. (2019). What is mental fatigue in elite sport? Perceptions from athletes and staff. Eur J Sport Sci, 1-10. doi:10.1080/17461391.2019.1618397 
Saw, A. E., Main, L. C., \& Gastin, P. B. (2015). Monitoring athletes through self-report: factors influencing implementation. J Sports Sci Med, 14(1), 137-146.

Shearer, D. A., Sparkes, W., Northeast, J., Cunningham, D. J., Cook, C. J., \& Kilduff, L. P. (2017). Measuring recovery: An adapted Brief Assessment of Mood (BAM+) compared to biochemical and power output alterations. J Sci Med Sport, 20(5), 512-517. doi:10.1016/j.jsams.2016.09.012

Slater, L. V., Baker, R., Weltman, A. L., Hertel, J., Saliba, S. A., \& Hart, J. M. (2018). Activity monitoring in men's college soccer: a single season longitudinal study. Res Sports Med, 26(2), 178-190. doi:10.1080/15438627.2018.1431535

Smith, M. R., Coutts, A. J., Merlini, M., Deprez, D., Lenoir, M., \& Marcora, S. M. (2016). Mental Fatigue Impairs Soccer-Specific Physical and Technical Performance. Med Sci Sports Exerc, 48(2), 267-276. doi:10.1249/MSS.0000000000000762

Smith, M. R., Fransen, J., Deprez, D., Lenior, M., \& Coutts, A. J. (2017). Impact of mental fatigue on speed and accuracy components of soccer-specific skills. Science and Medicine in Football, l(1), 48-52.

Smith, M. R., Marcora, S. M., \& Coutts, A. J. (2015). Mental Fatigue Impairs Intermittent Running Performance. Med Sci Sports Exerc, 47(8), 1682-1690. doi:10.1249/MSS.0000000000000592

Smith, M. R., Thompson, C., Marcora, S. M., Skorski, S., Meyer, T., \& Coutts, A. J. (2018). Mental Fatigue and Soccer: Current Knowledge and Future Directions. Sports Med, 48(7), 15251532. doi:10.1007/s40279-018-0908-2

Smith, M. R., Zeuwts, L., Lenoir, M., Hens, N., De Jong, L. M., \& Coutts, A. J. (2016). Mental fatigue impairs soccer-specific decision-making skill. J Sports Sci, 34(14), 1297-1304. doi:10.1080/02640414.2016.1156241

Thompson, C. J., Fransen, J., Skorski, S., Smith, M. R., Meyer, T., Barrett, S., \& Coutts, A. J. (2019). Mental Fatigue in Football: Is it Time to Shift the Goalposts? An Evaluation of the Current Methodology. Sports Med, 49(2), 177-183. doi:10.1007/s40279-018-1016-z

Varley, M. C., Gregson, W., McMillan, K., Bonanno, D., Stafford, K., Modonutti, M., \& Di Salvo, V. (2017). Physical and technical performance of elite youth soccer players during international tournaments: influence of playing position and team success and opponent quality. Science and Medicine in Football, 1(1), 18=29.

Winder, N., Russell, M., Naughton, R. J., \& Harper, L. D. (2018). The Impact of 120 Minutes of Match-Play on Recovery and Subsequent Match Performance: A Case Report in Professional Soccer Players. Sports (Basel), 6(1). doi:10.3390/sports6010022 